\title{
O NADA QUE RETORNA COMO O QUERER: PARALELOS ENTRE O NIILISMO, A VONTADE DE PODER E O ETERNO RETORNO NA FILOSOFIA DE NIETZSCHE
}

\author{
Jan Clefferson Costa de Freitas \\ Doutorando em Filosofia - UFPB-UFPE-UFRN
}

\begin{abstract}
RESUMO: Este artigo visa realizar uma verificação das relações estabelecidas entre o "niilismo", a "vontade de poder", e o "eterno retorno" no pensamento de Friedrich Nietzsche: para tanto, será demonstrado como os conceitos em questão se interligam dentro de sua filosofia, trazendo a luz de uma unidade conceitual nem sempre evidente nos aforismos do filósofo. Entrementes, será descrito como as expressões supramencionadas estabelecem paralelos com os temas nietzschianos da "morte de Deus", do "além-dohomem" e da "transvaloração de todos os valores", aumentando ainda mais a dimensão dessa unidade. Por fim, ao ser verificado como as duas tríades conceituais se interpenetram no cerne das obras de Nietzsche, a conclusão extraída será que a última tríade explica a primeira delas, sendo os conceitos contidos em ambas, respectivamente, compreendidos como sinônimos um do outro.
\end{abstract}

Palavras-chave: Niilismo; Vontade de Poder; Eterno Retorno.

\begin{abstract}
This article aims realize a verification of the relations established between the "nihilism", the "will to power", and the "eternal recurrence" in the Friedrich Nietzsche's thought: for this, it will be demonstrated how the concepts in question are related within his philosophy, bringing the light of a conceptual unity which is not always perceived in the philosopher's aphorisms. Meanwhile, it will be described as the above-mentioned expressions, establishes a parallel with the nietzschean themes of the "death of God", of the "beyond-man" and of the "transvaluation of all values", further increasing the dimensions of this unity. Finally, to be verified how the two conceptual triads are interpenetrates at the heart of Nietzsche's works, the conclusion to be draw is that the last triad explains the first one, being the concepts contained in both, respectively, understood as synonymous each other.
\end{abstract}

Keywords: Nihilism; Will to Power; Eternal Recurrence.

\section{O declínio de todos os sóis e o declínio do sol supremo: paralelos iniciais}

O niilismo é compreendido por Nietzsche como a história dos valores supremos. Para entender o essencial de tal história é necessário compreender o que constitui a essência do niilismo. Em termos gerais, "De caráter esquivo, ambíguo e de pouca clareza, o niilismo parece não aceitar definições e usos precisos, fixos e seguros" (MONTEIRO, 2010, p. 11). O niilismo em Nietzsche tem o seu advento anunciado pela sentença "Deus 
está morto", proferida pelo personagem louco que aparece no aforismo 125 de A Gaia Ciência [1882]. Na literatura crítica das obras do filósofo, o fragmento em questão é vastamente mencionado por extenso - a título de exemplo, Heidegger (2003, p. 476) o faz ao discorrer em seu ensaio a respeito da sentença nietzschiana: fazê-lo aqui talvez soasse repetitivo. Nietzsche também enxerga o niilismo como um estado psicológico no qual o sentido dos acontecimentos não reside em lugar algum, sendo aqui psicologia compreendida como uma ciência experimental que se debruça sobre os estados de ânimo e tipos de caráter: o desmoronamento dos valores cosmológicos, descrito no parágrafo 12 de $A$ Vontade de Poder [1900], apresenta o niilismo como um fato psicológico, como um estado de espírito. Nessa perspectiva:

Niilismo é então o tornar-se consciente do grande e duradouro desperdício de força, o tormento do em vão, a insegurança, a falta de oportunidade de recuperar-se de qualquer modo, de ainda repousar sobre alguma coisa - a vergonha de si mesmo, como de alguém que se tivesse enganado durante muito tempo (NIETZSCHE, 2008, \12, p. 31).

De acordo com Nietzsche, a ilusão de um além-mundo esvaziou nos homens o sentido deste mundo, os enfraqueceu e os fez inseguros diante da vida, os tornando irrecuperáveis e dependentes de se apoiar em algum ideal, vergonhosos de si. A Consumação do niilismo se dá quando o ideal supremo desmorona para dar lugar ao nada. Do nada que resta após o desmoronamento dos valores supremos nasce a condição de possibilidade para o surgimento de novos valores. A notícia da morte de Deus faz o niilismo estar à porta, trazendo consigo a descrença nas verdades supremas, a inexistência de um mundo verdadeiro e a falta de sentido no mundo aparente. O enfrentamento do humano com o nada vai gerando a criação: o nada é aquilo que faz a vida ter o desejo de desejar, que a entrega para o ato de criar e que, por consequência, também vigora tendo um caráter positivo, pois é aquilo que inquieta o ente humano e o impulsiona ao desconhecido - o niilismo tem no nada a sua máxima expressão.

A expressão "vontade de poder" representa, para Nietzsche, um vir a ser, isto é, a criação, destruição e recriação: o movimento da vida, o jogo da diferenciação, é a vontade de poder. "Vontade" significa o movimento em direção ao que se quer. "Poder" quer dizer o que foi alcançado e também superado. Ir além do poder alcançado oferece os elementos necessários para o acréscimo de mais poder. O incremento do poder vem para a sua manutenção e só existe a superação onde existir o enfrentamento: é preciso a confrontação com aquilo que oferece resistência para que haja a superação. A vontade de poder, movida 
em um fluxo eterno que sempre retorna, lança-se à procura de mais poder, transvalorando valores obsoletos e instaurando valores novos: "A transvaloração dos valores até aqui é, em primeiro lugar, uma transformação da valoração até aqui e a criação seletiva de uma nova necessidade valorativa" (HEIDEGGER, 2014, p. 484). Assim, Nietzsche pensa a vontade de poder sob o aspecto da transvaloração, como um movimento que após a derrocada dos valores supremos vai instaurar novos valores. Nas palavras do autor:

A vontade de poder. Tentativa de uma transvaloração de todos os valores - com essa fórmula expresso um contramovimento, no que toca ao princípio e à tarefa: um movimento que substituirá em algum futuro aquele niilismo consumado; mas que, todavia, o pressupõe, lógica e psicologicamente, que tão-somente pode vir sobre ele e a partir dele (NIETZSCHE, 2008, Pr. 4, p. 23).

Nietzsche concebe a vontade de poder como uma tensão entre a determinação e a indeterminação, movimento por meio do qual todas as possibilidades de realidade no mundo da vida são configuradas, superando com afirmações as negações estabelecidas pela moral degenerada contra a vida e contra o mundo. Em outras palavras: "A vontade de poder é o novo princípio de determinação de todas as configurações possíveis do real. Por meio desse novo princípio viabiliza-se ao mesmo tempo a superação da negação e o aparecimento de uma afirmação dominante" (CASANOVA, 2003, p. 342). A afirmação dessa novidade que se contrapõe ao convencionado é dizer sim sempre, o que consiste no estabelecimento de uma nova perspectiva acerca do mundo e da vida, na qual estes últimos estão sendo os grandes fios-condutores da vontade de poder.

O mundo não proposita nem intenciona a sua ausência de sentido. O devir segundo Nietzsche é "o eterno retorno", a expressão da própria vida; retorno eterno que não é só mero fluir, mas que também é a vontade de poder, ou seja, a retomada da vida para o gerenciamento do poder. O eterno retorno como a mais inexorável lei de repetição das mesmas coisas: querer para o poder e eternidade em um movimento de vir a ser que se repete sem cessar. Nietzsche compreendia a noção de eterno retorno como um "convite a viver cada momento, de modo que pudesse retornar sem susto. Esse pensamento deveria fazer o momento cintilar e conferir à vida a dignidade do Inaudito" (SAFRANSKI, 2001, p. 164). O eterno retorno ata e elimina a fragmentação de tempo e da vida, formulando a existência como unidade que retorna sobre si: aponta para a finitude da existência e também para a eternidade do tempo. O passado e o futuro se chocam criando o instante. O presente não se eterniza ao estar parado. O eterno retorno está sendo pensado por Nietzsche a partir do devir. A relatividade carece de consistência, assim como o ser 
necessita de aparição: o retorno à consistência do inconsistente é a vontade de poder. $\mathrm{O}$ que carece de consistência sempre retorna em um movimento de querer ser consistente. Em A Gaia Ciência, o pensamento da eterna recorrência está expresso com a seguinte formulação:

Esta vida, como você a está vivendo e já viveu, você terá de viver mais uma vez e por incontáveis vezes; e nada haverá de novo nela, mas cada dor e cada prazer e cada suspiro e pensamento, e tudo o que é inefavelmente grande e pequeno em sua vida, terão de lhe suceder novamente, tudo na mesma sequência e ordem (NIETZSCHE, 2012, \ 341, p. 205).

O divino é o movimento de pôr e retirar que eternamente retorna: tal movimento é a vontade de poder que perpassa o eterno retorno - desse modo, "o binômio vontade de poder/eterno retorno do mesmo devolve ao mundo a sua natureza divina, e todas as suas faces passam ao mesmo tempo a se mostrar como tal" (CASANOVA, 2003, p. 347). É possível suportar "o mais pesado de todos os pesos"? O pesar do eterno retorno? Sim: vindo a ser o que se é na relação entre o passado e o futuro. Imagine um fio de linha com duas pontas no qual uma pessoa dará um nó simples. As duas pontas do fio são respectivamente o futuro e o passado. $\mathrm{O}$ nó que ata os dois antípodas do tempo é o presente. O instante ata em um único ato o passado e o futuro, sendo o encontro do que já aconteceu com o que vai acontecer. E aí, a partir do que já é, ser: dever ser e poder ser venha a ser o que tu és, é o convite que Nietzsche faz. Querer significa suportar a carga psíquica das escolhas que são feitas, para sempre. O crescimento se mantém a partir do declínio. A superação implica em um movimento: tal movimento não é apenas eterno retorno, mas também é transvaloração e vontade de poder. Em suma, a eterna retomada da vontade como aquilo que se quer que seja e como o que precisa ser, "a inesgotável plenitude da vida na sua alegria e na sua dor" (HEIDEGGER, 2012, p. 94): é isso o eterno retorno.

\subsection{A superação da ilusão e a transvaloração da decadência: paralelos intermediários}

Os valores são postos a partir de que lógica? A partir da negação do mundo real e na postulação de um mundo ideal. A vontade de poder transvalora os valores que até então instituíram o niilismo. O poder é constituído pelo acréscimo de mais poder. É pondo que se retorna sobre si mesmo como o eterno movimento de pôr: "somente a partir da essência do eterno retorno do mesmo que é possível apreender o cerne essencial mais íntimo da 
vontade de poder e a sua necessidade" (HEIDEGGER, 2014, p. 485-486). Cada existência se constitui tendo os valores como base, as metas como sentido, o princípio como fim. $\mathrm{O}$ eterno retorno do mesmo sendo pensado como o eterno retorno do nada: o mais terrível de todos os pensamentos, sempre trazendo aquele que, para Nietzsche, é "o mais inquietante de todos os hóspedes", a saber, o niilismo, a nulificação dos supremos valores. Desta feita, o autor lança o desafio para o leitor:

Pensemos esse pensamento em sua forma mais terrível: a existência, tal como é, sem fim nem objetivo, mas inevitavelmente retornando, sem um finale no nada: o eterno retorno. Essa é a forma mais extrema do niilismo: o nada (o sem sentido) eterno! (NIETZSCHE, 2008, \& 55, p. $52)$.

$\mathrm{Na}$ tensão do arco os extremos tendem a se tocar: em tais ocasiões, o eterno retorno acontece. O "espírito de vingança" contra a vida é a lógica do niilismo: um movimento de separação após a tensão - o afrouxamento do arco -, no qual "a vingança relaciona-se previamente com toda reflexão até hoje empreendida pelo homem" (HEIDEGGER, 2012, p. 97). O niilismo apresentado pela decadência dos valores cosmológicos apresenta a sua face positiva na necessidade de valores novos. A elaboração e a constituição de novos valores são a essência do niilismo. O niilismo não pode ser compreendido de um modo uniforme: existem para Nietzsche muitos modos de nilismo, podendo este vir a ser sintetizado em uma grande ambiguidade - "Niilismo como sinal de poder incrementado do espírito: como niilismo ativo [...] Niilismo como decadência e recuo do poder do espírito: o niilismo passivo" (NIETZSCHE, 2008, \22, p. 36). Os valores supremos declinam por estarem propondo uma coisa que não é possível. Assim, a transvaloração pode ser concebida como a inversão radical dos valores vigentes.

O que é o advento do niilismo? É a consciência de que o niilismo é a lógica da história da metafísica Ocidental - ou como enxerga a interpretação heideggeriana: "Niilismo é aquele processo histórico por meio do qual o domínio do suprassensível se torna nulo e caduco, de tal modo que o ente mesmo perde o seu valor e o seu sentido" (HEIDEGGER, 2014, p. 482). A morte de Deus é a morte do ente supremo, dos supremos valores: uma obra perpetrada pelos homens, cuja essência consiste na destituição do mundo verdadeiro. Essa metáfora "descreve uma imposição histórica oriunda dos próprios desdobramentos do pensamento metafísico e exige de todos os que se encontram sob a influência dessa imposição uma nova tomada de posição" (CASANOVA, 2003, p. 338). A supressão do valor supremo faz deixar de existir um norte, uma referência para o homem: os valores desmoronam para dar lugar ao nada. A essência do mundo verdadeiro é 
perdida após a derrocada dos valores cosmológicos. Com a morte de Deus, o mundo suprassensível é destituído, e, o mundo do devir, torna-se o único mundo possível: o mundo sensível não tem sentido e o mundo suprassensível não existe - dessa tensão de forças o niilismo emerge.

Os supremos valores declinam por não poderem se estabelecer. O que deveria ser não é o que é: o mundo ideal é inexistente e sem consistência. O que vai constituir a essência do niilismo? A negação de que o mundo é um vir a ser. O único mundo verdadeiro, para Nietzsche, é uma monstruosidade movida por antagonismos irreconciliáveis: o pensamento idiossincrásico do pensador supramencionado reconheceria que, "na efetividade, não há nada de fixo, nada permanente, mas somente a torrente incessante do vir-a-ser e perecer" (MÜLLER-LAUTER, 2009, p. 42). O eterno retorno como um ir e voltar que não descansa e que não repousa:

O mundo persiste; ele não é nada que se torne, nada que passe. Ou antes: ele torna-se, passa, mas nunca começou a tornar-se e nunca cessou de passar - ele mantém-se em ambos... Vive de si mesmo: seus excrementos são o seu alimento (NIETZSCHE, 2008, \1066, p. 510).

O mundo se retroalimenta do que ele excreta. O devir é a vida sendo contemplada como sem sentido: necessita-se de um mundo com algum significado. O sentido é visto como o valor ou a meta posta pela vontade de poder. Se o mundo tal qual ele é não é verdadeiro, o devir não desemboca em ser algum. O devir é a vontade de poder que desvalora e transvalora: "a vontade de poder, entendida como princípio fundamental da vida, deveria fundamentar uma revisão de todos os conceitos morais, isto é, a transvaloração de todos os valores" (SAFRANSKI, 2001, p. 260-261). O princípio da vontade de poder, somente o louco compreende e enuncia, ou seja, a morte de Deus, que desembocará em uma transvaloração, por meio da qual o ser humano superará a ilusão e dará sentido à realidade, retirando os valores atrasados do cenário para assim, superá-los e instaurar novos valores.

De que modo Nietzsche pensa o nada a partir do valor? Chave para a compreensão do niilismo no autor. $O$ inconsistente que retorna eternamente: a indeterminação sempre retorna, sem descanso. A vontade de poder só pode se constituir como valor. Valor se compreende a partir da vontade de poder. O valor é a garantia da manutenção, conservação e elevação da vontade de poder: assim sendo, nem este nem aquela podem ser pensados em separado. Os valores postulados como condições de crescimento da vontade de poder são as bases de compreensão do niilismo em Nietzsche: 
Valor é a suprema quantidade de poder que o homem consegue incorporar em si - o homem: não a humanidade... Humanidade é antes um meio do que um fim. Trata-se do tipo: a humanidade é meramente o material de ensaio, o imenso excesso de malogrados: um campo de ruínas... (NIETZSCHE, 2008, 』 713, p. 360).

No pensamento heideggeriano sobre a vontade de poder em Nietzsche, "a vontade prefere querer o nada a nada querer. Pois como vontade de poder, a vontade é poder para o poder" (HEIDEGGER, 2014, p. 504); afinal, o querer é a essência da vontade e a vontade é o que move o ser humano em direção desse poder. Crescer para a vontade de poder é criar novas condições de aparição. Poder não é a condição de ter domínio, mas sim o estado de estar entregue às condições da própria vida. É no abandono dos valores vigentes que se faz possível o fortalecimento da vontade de poder: vontade sendo pensada como aquilo que se ergue para ser e que, no entanto, ainda não é. O reconhecimento da vontade de poder como princípio abre caminho para a transvaloração e também para a superação do niilismo.

O medo do vazio é o ponto de partida fundamental do querer humano, a vida justificada como uma busca pelo nada, a anulação das próprias possibilidades da vontade, das suas condições essenciais, com o trágico desfecho de uma condição humana, demasiadamente humana, a dissolução completa, o esgotamento dos possíveis, a morte: diante de impessoal horror, o querer constitui a essência da vontade de poder. A vontade vai perdendo o ânimo ao buscar por um sentido que não existe, como o louco que procura por Deus e não o encontra. A morte do divino agiganta o ser humano:

Existe um lago que um dia se negou a escoar, e formou um dique onde até então escoava: desde esse instante ele sobe cada vez mais. Talvez justamente essa renúncia nos empreste a força com que a renúncia mesma seja suportada; talvez o homem suba cada vez mais, já não tendo um deus no qual desaguar (NIETZSCHE, 2012, \285, p. 171).

Segundo Nietzsche, Deus pode ser pensado como aquilo que permite ao homem se manter na vida: sem a crença em Deus, isto é, com a sua renúncia, a vida seria impossível; logo, ao constatar que Deus está morto, ao homem só resta o niilismo: a morte de Deus pode ser pensada como a causa primordial de todo o niilismo, mas também como abertura para uma nova valoração que a vontade de poder faz aparecer. Conforme ressalta Eugen Fink em A Filosofia de Nietasche [1960], “o conhecimento da vontade de poder exige ao mesmo tempo o conhecimento da morte de Deus, e vice-versa. Ambas as ideias têm uma conexão interna" (FINK, 1977, p. 82): a morte de Deus e a vontade de poder se entrelaçam 
na destruição dos valores antigos e na instauração dos valores novos, isto é, no niilismo, realizando, respectivamente, a sua transvaloração e posterior superação.

Quando se percebe que o sujeito não é o fundamento da realidade, abre-se com isso uma possibilidade de transvalorar: a superação da metafísica e do niilismo. Por qual motivo é necessário superar a metafísica? Porque a metafísica Ocidental se condicionou a ter no sujeito o seu cerne. Contrariando a tradição do pensamento metafísico, na crítica à metafísica feita por Nietzsche, "a noção de sujeito perde o estatuto referencial que desfrutava outrora, para funcionar doravante apenas como indicativo axiológico de certo dinamismo potencial" (ONATE, 2000, p. 121): a metafísica do sujeito é um ponto de vista restrito, uma perspectiva limitada, que quando submetida ao enfoque da vontade de poder, apresenta-se de um modo invertido, mais expandido, perdendo as suas limitações e nunca mais se restringindo. $\mathrm{O}$ que constitui a essência do niilismo? A busca de um sentido para o que acontece e que não está no acontecer. Em Crepúsculo dos Ídolos [1888], Nietzsche faz saber que:

Se um filósofo pudesse ser niilista, ele o seria porque encontra o nada por trás de todos os ideais do ser humano. Ou nem sequer o nada - mas apenas o que nada vale, o que é absurdo, doentio, covarde, cansado, toda espécie de borra da taça esvaziada de sua vida (NIETZSCHE, 2014, IX, $\int 32$, p. 81).

O nada é pensado por Nietzsche como o pano de fundo que encobre os ideais do ser humano. Niilista é aquele que, por trás de todos os ideais humanos, enxerga o nada como o máximo valor. O niilismo é a lógica que governa a própria história, não é apenas mais um movimento inserido na história. O eterno retorno como a eterna retomada da vida que não releva sentido algum a não ser em si mesma. Só se pode falar da vontade a partir do poder alcançado que foi alcançado para ser ultrapassado. O nada sendo trazido como aquilo que é profundo e que vigora como valor que se eleva para ser: pensar o nada é pensar o ser. Supremo valor é aquilo que confere à existência um norte: este supremo valor, a unidade na qual o homem poderia repousar, é Deus.

A queda do mundo suprassensível, proposta e intentada por Nietzsche, realiza uma inversão do platonismo e provoca a instauração da morte de Deus, que culmina no desabamento do mundo ideal: " $\mathrm{Na}$ medida em que o suprassensível, o além e o céu são abolidos, a única coisa que resta é a terra” (HEIDEGGER, 2014, p. 486). Com isso o mundo aparente apresenta-se como o único mundo passível de realidade. O niilismo também pode ser pensado como a tentativa de universalizar o nada? $\mathrm{O}$ niilismo pode ser interpretado como a erradicação valorativa da qual decorre a postulação de valores novos. 
O niilismo radical, para Nietzsche, é a total inconsistência da existência sendo pensada como uma convicção; o verdadeiro se transforma na crença moral e esta, por sua vez, projeta um mundo para além deste como resposta. Assim, "Nietzsche introduz na filosofia os conceitos de sentido e de valor, promovendo com isso a exclusão de fenômenos morais e afirmando existir uma interpretação moral dos fenômenos" (AZEREDO, 2000, p. 34). A radicalidade do niilismo se manifesta na convicção de que o mundo da vida é inconsistente nos seus valores mais elevados:

O niilismo radical é a convicção de uma absoluta inconsistência da existência quando se trata daqueles valores que se reconhecem como os mais altos, adicionado o entendimento de que nós não temos o mínimo direito de acrescentar um além ou um em-si das coisas que seja divino ou moral de carne e osso (NIETZSCHE, 2008, \$3, p. 29).

A busca pelo nada e a anulação da vontade são quereres; mesmo que seja por nada, a própria vida ainda busca alguma coisa. A vida não pode ser valorada, pois em si mesma é desprovida de valores. O valor é o condicionado e sendo assim não pode impor a condição. Nenhum valor, para Nietzsche, pode ser universalizado: não existem valores que possam dar conta de toda a existência, da totalidade da vida. O nada é a condição de possibilidade da própria origem. A cena da morte de Deus sendo pensada como a derrocada dos valores supremos faz com que a ilusão psicológica causada pelo seu assassinato seja a causa do niilismo. Destarte, “o deicida tem de tornar-se Deus, portanto além-do-homem, ou despencará na banalidade - essa a ideia que Nietzsche desenvolve nessa cena" (SAFRANSKI, 2001, p. 248). Deus está sendo pensado por Nietzsche como sendo um valor supremo e o niilismo, por representar a derrocada destes valores, traz na metáfora da morte de Deus o seu advento.

As necessidades psicológicas deram origem ao mundo suprassensível: esse mundo é responsável pela manutenção da própria vida, pois os valores universais oferecem sentidos à vida. $\mathrm{O}$ que devia ser é o ideal: essa lógica enfraquece a vontade de viver. $\mathrm{O}$ mundo suprassensível é inatingível porque não existe. Como a moral se relaciona com os valores cosmológicos? As forças constitutivas do mundo ideal se revelam como ficção, como aquilo que confere sentido e também permite à vida se manter:

A moral protegeu a vida diante do desespero e do salto no nada em homens e estamentos que foram subjugados e oprimidos por homens: pois a impotência contra os homens, não a impotência contra a natureza, produz o amargor mais desesperado (NIETZSCHE, 2008, $\$ 55$, p. 53). 
A vontade se afirma com a natureza sobre o desespero amargurado dos moralistas e impotentes de todos os tipos: o pessimismo como decadência é a forma prévia do niilismo - dizer que a vida não tem valor quer dizer que o condicionado não condiciona. $\mathrm{O}$ pensamento fundamental esboçado por Nietzsche em Assim Falava Zaratustra [1883] é o eterno retorno e o além-do-homem, cuja afirmação leva o homem à superação do niilismo, ao realizar o movimento necessário para a transvaloração de todos os valores. Em Para Além de Bem e Mal [1886] está escrito que o além-do-homem é "o ideal do homem mais exuberante, mais vivo e mais afirmador do mundo, que não só aprendeu a se resignar e suportar tudo o que existiu e é, mas deseja tê-lo novamente, tal como existiu e é, por toda a eternidade" (NIETZSCHE, 2005, \56, p. 54). O niilismo é superado quando se diz um sim à vida, afirmando-a como sendo uma expressão para a vontade de poder: assim o alémdo-homem se coloca. Para Nietzsche, o mundo inatingível não pode ser conhecido porque não pode ser alcançado. A supressão do mundo verdadeiro também suprime o sentido do mundo aparente. Dizer que o homem matou Deus significa dizer que a tentativa de uma transvaloração foi realizada e que agora novos valores podem ser postos.

As necessidades morais aparecem como vontade de inverdade; onde há valor de verdade, de acordo com Nietzsche, ainda é possível viver. Onde o niilismo se instaura nada há para ser alcançado. Os valores não são o espelho do mundo. A inversão dos valores vigentes até então é o desmoronamento dos valores supremos. As categorias de "fim", "unidade" e "ser" incutem no mundo valores: a suspensão das categorias em questão transforma o mundo em sem-valor.

O fato de o mundo não valer o que acreditávamos é aproximadamente a coisa mais segura de que a nossa desconfiança enfim se apoderou. Quanto mais desconfiança, mais filosofia. Nós nos guardamos de dizer que o mundo vale menos: hoje nos parece mesmo ridículo que o homem pretenda inventar valores que devem exceder o valor do mundo real (NIETZSCHE, 2012, \346, p. 213).

Ser, unidade e fim: os filtros de valor para o real do ente humano - filtros estes que não são perpassados pela essência das coisas e que não se projetam sobre as coisas da essência. A desvalorização dessas categorias faz o todo perder o valor: de tal desvaloração, o niilismo vem à tona. A transvaloração não é a destruição de todos os valores: é a superação que conduz ao surgimento de uma nova moral, de valores instituídos pela vontade de poder, e o niilismo, pode ser compreendido pela transvaloração, tendo a vontade de poder como princípio. Em poucas palavras: o melhor professor, para 
Nietzsche, é o mundo, pois o mundo, não tem o que dar; não existem valores para serem valorados, é preciso transvalorar.

\subsection{O nada que retorna como o querer: paralelos finais}

O desmoronamento dos valores sendo pensado a partir do movimento e ações humanas. A morte de Deus como a ausência de um fundamento último da realidade. O niilismo é a negação das finalidades da existência, a suprema afirmação do eterno nada: “A sentença Deus está morto encerra em si mesma a constatação de que esse nada se expande. Nada significa aqui: ausência de um mundo suprassensível, imperativo" (HEIDEGGER, 2003, 479). A morte de Deus faz o além-mundo se tornar fábula: a inversão do platonismo converte o mundo sensível em verdadeiro. Poucos percebem o advento do niilismo porque não percebem a morte de Deus. O niilista mais perfeito é aquele que esgota o não à vida para poder dizer sim a ela:

Quiséssemos simplesmente nos designar, como uma expressão mais velha, por ateu ou ímpio, ou ainda imoralista, não acreditaríamos nem de longe estar caracterizados com isso: somos as três coisas num estágio muito adiantado para que se compreenda, para que vocês compreendessem, senhores curiosos, em que estado de ânimo alguém assim se encontra (NIETZSCHE, 2012, \$346, p. 212).

A lógica quer dizer que a vida não pode resultar numa contradição, mas a vida se coloca de um modo inconsistente, como algo sem valor, contrariando a razão como fundamento e a lógica como princípio. Declinar é primordialmente movimento. O platonismo declina quando o mundo verdadeiro perde a sua consistência. Um niilista pleno é aquele que conseguiu transvalorar todos os valores, consumando a morte de Deus e afirmando o eterno retorno com um sim à existência: "É impensável, para Nietzsche, a produção de novos valores sem esse querer, sem esse grande sim à vida" (SCHÖPKE, 2005, p. 207). A vontade de poder é o princípio gerativo de um conjunto de forças que na sua concentração e confrontação, vai mantendo a realidade. O ativismo demonstra autonomia em relação à vontade e à vida: constitui afirmação da vontade de poder. O já visto e posto precisa ser desconsiderado para que possa ser feita a história.

Nietzsche compreende toda metafísica como um resultado do nilismo: para o filósofo, o que governa a história é um espírito de vingança contra a vida; "vingança é a recalcitrância da vontade contra o tempo e isto quer dizer: contra o passar e sua transitoriedade" (HEIDEGGER, 2012, p. 101). A negação do vir a ser como halitose de 
mediocridade: o desprezo pela vida que a conservou sem destruição, mas que a fez se degenerar sob o controle da moral. Os valores supremos são criados apenas pela carência de um referencial com o qual se possa nortear o homem: "também isso é ainda a exigência de apoio, de suporte, em suma, o instinto de fraqueza que, é verdade, não cria religiões, metafísicas, convicções de todo tipo - mas as conserva" (NIETZSCHE, 2012, 』 347, p. 214). O além-mundo passa a ser visto como aparência, sem sentido, sem realidade, necessitando desabar para dar lugar ao mundo sensível, aqui na terra e não mais além: "Quando o mundo verdadeiro suprassensível cai, o mundo do devir mostra-se muito mais como a única realidade, isto é, como o mundo propriamente dito e como o único mundo verdadeiro" (HEIDEGGER, 2014, p. 507). A pobreza da vida, a invalidade do mundo, o desprezo pelo corpo, são as bases de sustentação do niilismo. Vida e morte se complementam: uma coisa se segue da outra; com a morte, a vida cresce e continua em um eterno movimento.

A vontade de poder é a vida como ela mesma se determina, para crescer, não para ater-se dentro de limites: "Por isso, afirmar a existência é querer primeiramente que ela sempre retorne, é amá-la de tal modo que ela seja desejada de maneira irrestrita e incondicional" (SCHÖPKE, 2005, p. 208). A última forma de niilismo é a descrença absoluta em um mundo para além deste: "o niilismo torna-se agora a descrença expressa em algo, assim como um mundo erigido sobre aquilo que é sensível e que vem a ser [sobre o físico], isto é, um mundo metafísico" (HEIDEGGER, 2014, p. 507). O mundo revela-se sem sentido e sem unidade. No niilismo como a lógica da história que constitui a metafísica e o Ocidente, o que importa é a disjunção entre os opostos que constituem a tradição do pensamento metafísico: quando se ocupa a posição de criador, é necessário não se prender à tradição.

$\mathrm{Na}$ história do niilismo, o niilismo é a história: niilismo assim sendo pensado sob o prisma da vontade de poder. Como se pode superar o niilismo? Dizendo sim ao eterno retorno. A história é pensada por Nietzsche como sendo isenta de finalidade; já o niilismo, é visto pelo pensador como um processo de dissolução, como a lógica da história. Da nulificação nasce o desejo de aventura: vontade de poder como exposição súbita de nada para nada, da vida como um todo. O nada é a essência do niilismo: o niilismo tem que ser pensado a partir do nada. A vontade de poder, quando esgota as suas possibilidades, faz a metafísica consumar-se, esvaziar-se e chegar ao fim. Depreende-se a partir daí que a vida precisa lançar-se para além dos valores criados, valorando e desvalorando a cada um deles; que as finalidades da existência permitem ao homem sentir-se valoroso diante de algo, lhe 
trazendo a sensação de possuir algum valor; e que os valores manifestos estão postos para serem destruídos, superados: a vida é um jogo de construção e destruição, de diferenciações. No pensamento nietzschiano, a relação entre o niilismo e a desvaloração de todos os valores se estabelece na superação destes últimos para que o querer possa lançarse sobre mais poder, instaurando valores jamais antes vistos ao transvalorar os valores antigos: o movimento do incremento para mais poder é a condição para a suplantação do poder alcançado e o nada - aquilo que menos importa -, para Nietzsche, é aquilo que mais tem valor. A vontade de poder instaura os valores que o niilismo faz derrocar e o niilismo faz derrocar os valores que a vontade de poder instaura, em um fluxo incessante que se repete eternamente: assim relacionam-se o niilismo, a vontade de poder e o eterno retorno na filosofia de Nietzsche.

\section{REFERÊNCIAS BIBLIOGRÁFICAS}

AZEREDO, V. D. Nieţssche e a Dissolução da Moral. Discurso Editorial: São Paulo, 2000.

FINK, E. A Filosofia de Nietzsche. Trad. Jan Clefferson Costa de Freitas, Alianza Editorial: Madri, 1977.

CASANOVA, M. A. A religião da Terra: O Lugar do Sagrado no Pensamento de Friedrich Nietzsche. In: A Fidelidade à Terra: Assim Falou Nietzsche IV (Org. Charles Feitosa, Miguel Angel de Barrenechea et al). DP\&A: Rio de Janeiro, 2003.

HEIDEGGER, M. A Sentença Nietzsschiana Deus está Morto. Trad. Marco Antônio Casanova. v.5, n.2, p.471-526, São Paulo: dez. 2003.2 Disponível em $<$ http://pepsic.bvsalud.org/scielo.php?script=sci_arttext\&pid=S1517$24302003000200008 \& \operatorname{lng}=$ pt\&nrm $=$ iso $>$. acessos em 26 jan. 2017. . Nietzssche. Trad. Marco Antônio Casanova. $2^{\mathrm{a}}$ Ed. Forense Universitária: Rio de Janeiro, 2014.

- Quem é o Zaratustra de Nietz̧sche? In: Ensaios e Conferências. Trad. Emmanuel Carneiro Leão, Gilvan Fogel et al. 8ª Ed. Vozes: Petrópolis, 2012.

MONTEIRO, F. P. O Niilismo Social: Anarquistas e Terroristas no Século XIX. Annablume, São Paulo: 2010.

MULLER-LAUTER, W. Nietzsche: sua filosofia dos antagonismos e os antagonismos de sua filosofia. Trad. de Clademir Araldi. Ed. Unifesp: São Paulo, 2009. 
NIETZSCHE, F. W. Além do Bem e do Mal: Prelúdio a uma Filosofia do Futuro. Trad. Paulo César de Souza. Companhia das Letras: São Paulo, 2005. - A Gaia Ciência. Trad. Paulo César de Souza. Companhia das Letras: São Paulo, 2005.

. Assim Falava Zaratustra: Um Livro para Todos e para Ninguém. Trad. Mário Ferreira dos Santos. $4^{a}$ Ed. Vozes: Petrópolis, 2010. - A Vontade de Poder. Trad. Marcos Sinésio Pereira Fernandes, Francisco José Dias de Moraes. Contraponto: Rio de Janeiro, 2008. . Crepúsculo dos Ídolos: ou Como se Filosofa com o Martelo. Trad. Paulo César de Souza. Companhia das Letras: São Paulo, 2014.

ONATE, A. M. O Crepúsculo do Sujeito em Nietzsche: ou como abrir-se ao filosofar sem metafísica. Discurso Editorial: São Paulo, 2000.

SAFRANSKI, R. Nietæssche: a Biografia de uma Tragédia. Trad. Lya Lett Luft. Geração Editorial: São Paulo, 2001.

SCHÖPKE, R. O Eterno Retorno de Nietzssche: Repetição ou Seleção? In: A Diferença (Ogr. Luis B. L. Orlandi). Editora da Unicamp, São Paulo: 2005. 